\title{
Neonatal secretion of gastrin and glucagon
}

\author{
I. M. ROGERS, D. C. DAVIDSON, J. LAWRENCE, JOY ARDILL, and K. D. BUCHANAN \\ From the Departments of Surgical and Medical Paediatrics, Stobhill Hospital, Glasgow, and the Department of \\ Medicine, Queen's University, Belfast
}

\begin{abstract}
Rogers, I. M., Davidson, D. C., Lawrence, J., Ardill, J., and Buchanan, K. D. (1974). Archives of Disease in Childhood, 49, 796. Neonatal secretion of gastrin and glucagon. Plasma gastrin and glucagon levels were estimated in mothers after labour, and in their babies at birth and on the fourth day of life. The newly born baby appears to secrete gastrin independently and the plasma levels are higher on the fourth day of life. The cord gastrin level is lower when labour is induced or augmented by the intravenous infusion of oxytocin. Our results do not exlude the possibility that gastrin is transferred from mother to baby during a spontaneous labour. Such a maternal component of cord gastrin may be responsible for neonatal gastric hyperacidity.

The mean cord glucagon level is higher than the maternal level at birth and the fourth day level is higher than the cord level. The C-terminal reactive glucagon-like immunoreactivity (C-GLI) in the cord blood is lower when oxytocin has been used during labour. Maternal or placental transfer of C-GLI during labour to the spontaneously born baby is one possible explanation of this finding.

The raised glucagon levels on the fourth day may explain why there is low gastric acidity at this time despite the gastrin level being higher than at birth. No relation could be deduced between the C-GLI, i.e. pancreatic glucagon level, and the blood glucose level either at birth or on the fourth day of life.
\end{abstract}

Gastric hyperacidity in term babies was first recognized in the early part of this century (Hess, 1913; Griswold and Shohl, 1925). This hyperacidity is present within a few hours of birth, reaches a peak within 24 hours, and declines quite sharply after about 2 days (Miller, 1941; Ebers, Smith, and Gibbs, 1956; Avery, Randolph, and Weaver, 1966). Levels of acidity comparable with those seen in the first 2 days of life are not again encountered until the child is 3 years or more (Levinson and MacFate, 1937).

Miller (1941) thought that this early wave of hyperacidity would best be explained by the transfer of a gastric secretory hormone across the placenta from mother to baby. Little was known about such hormones then; indeed, the importance of the hormone gastrin in causing gastric acid secretion in adults has only been established in recent years (Gregory and Tracy, 1964). Other polypeptide hormones, notably glucagon, are known to reduce the acid secretory effect of gastrin.

We report here the plasma levels of gastrin and glucagon in mothers after labour and in their babies

Received 8 April 1974. at birth and on the fourth day of life. Gastrin levels in the neonate have not previously been reported. Previous reports about glucagon in the newly born baby have not distinguished between C-terminal reactive glucagon-like immunoreactivity (GLI) and N-terminal reactive GLI, nor have measured glucagon levels as late as the fourth day.

\section{Methods and materials}

Maternal and cord venous samples were taken at birth from 22 mothers and babies. A further $3 \mathrm{ml}$ venous sample was taken from 19 of these babies on the fourth day of life after a 4-hour fast. 2 of the original babies were excluded because regular sedation with phenobarbitone had been required and a third baby was excluded because of early discharge from hospital. The blood glucose was also measured in the cord and fourth day samples and informed consent was obtained from the infants's mothers.

Labour was spontaneous in 11 mothers and was induced by rupture of membranes and an intravenous infusion of oxytocin in 9 mothers. The 2 remaining mothers had an oxytocin infusion during the course of an otherwise spontaneous labour and were included in the oxytocin group. Pethidine was routinely administered for obstetric analgesia. There was no significant 
difference in the parity, duration of labour $(P>0.1)$, and frequency of postmaturity between the oxytocin and non-oxytocin groups (see Table).

\section{TABLE}

Mean duration of labour, number of primigravidae, and number of postmature mothers in the groups receiving or not receiving oxytocin

\begin{tabular}{l|c|c}
\hline & Oxytocin (11) & No oxytocin (11) \\
\hline $\begin{array}{l}\text { Mean duration of } \\
\text { labour (hr) }\end{array}$ & $10 \cdot 9 \pm 1 \cdot 9 \star$ & $7 \cdot 3 \pm 1 \cdot 3^{\star}$ \\
$\begin{array}{l}\text { No. of primigravidae } \\
\text { No. postmature }\end{array}$ & 6 & 4 \\
\hline
\end{tabular}

$\star 11$ mothers in each group; there was no difference in the mean duration of labour between the two groups $(P>0 \cdot 1)$.

All the babies were mature; there was no asphyxia at birth and, with one exception, they were all being artificially fed on the fourth day. The birthweight ranged from $2 \cdot 41$ to $4 \cdot 12 \mathrm{~kg}$. The venous sample was collected in a lithium heparin tube and was centrifuged on withdrawal. The separated plasma was stored at $-20^{\circ} \mathrm{C}$ and the gastrin and glucagon measurements were performed by radioimmunoassay.

Gastrin assay. The antisera used was raised to synthetic human gastrin I (2-17) conjugated to ov-albumin using glutaraldehyde. Synthetic human gastrin I was labelled with ${ }^{125}$ Iodine (Radiochemical Centre, Amersham) and standard gastrin was obtained from the Medical Research Council. Separation of antibody-bound from free hormone was achieved using dextran-coated charcoal. Cross-reaction with cholecystokinin-pancreozymin is 1 in 10,000 on a molar basis (Ardill, 1973).

Glucagon assay. The plasma was extracted by ethanol in order to rid the plasma of proteases (Heding, 1971). Pancreatic glucagon (Novo) was iodinated according to the method of Jorgensen and Larsen (1972). Each plasma sample was assayed by two antibodies to pancreatic glucagon, one of which, YY57, showed cross-reaction with large gut glucagon-like immunoreactivity (GLI), and the other, YY89, showed no cross-reaction with large gut GLI (Murphy, Buchanan, and Elmore, 1973). These antibodies have been characterized further in that YY89 reacts with C-terminal fragments of pancreatic glucagon (supplied by Dr. W. Brommer, Eli Lilly). The material in the plasma measured by YY89 is referred to as C-terminal reactive GLI (C-GLI) and that by YY57 as N-terminal reactive GLI (N-GLI).

This departure from classical terminology has been taken because small gut GLI reacts with YY89, and there may be conversion of large gut GLI to small gut GLI in plasma or tissues (Murphy et al., 1973; Buchanan et al., 1974). In most instances it is likely that plasma C-GLI levels represent pancreatic glucagon secretion, whereas
N-GLI levels receive a considerable contribution from the gut. The assays could detect $15 \mathrm{pg} / \mathrm{ml} \mathrm{N}-\mathrm{GLI}$ and $30 \mathrm{pg} / \mathrm{ml} \mathrm{C-GLI}$.

\section{Results}

Gastrin levels.

Maternal and cord gastrin. The mean cord gastrin was greater than the maternal level in the group as a whole $(P<0.005$, no. $=22)$; this was due entirely to the contribution of the spontaneous labour group, as there was no significant difference when the oxytocin-induced babies were considered separately (Fig. 1). There was a significant

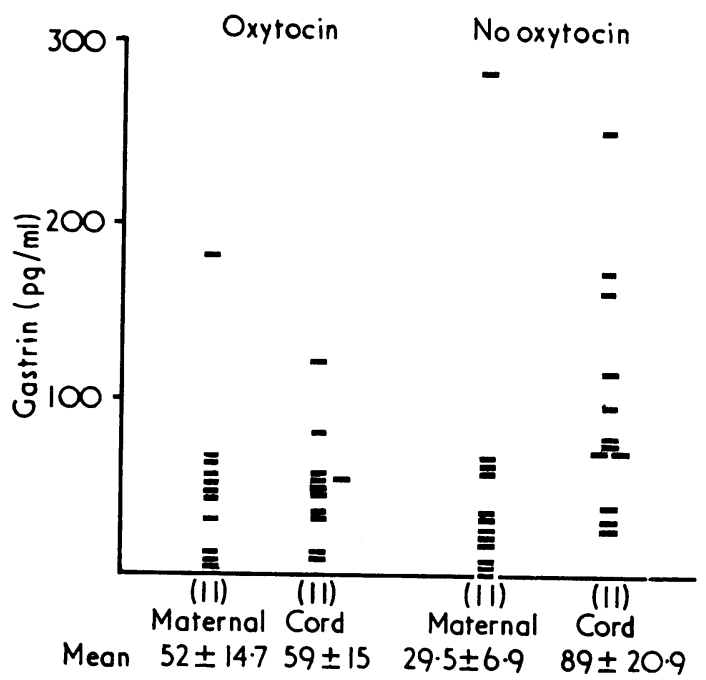

FIG. 1.-Plasma gastrin levels in mothers after labour and in the cord vein. The number of samples from cases receiving and not receiving oxytocin is shown.

difference $(P<0.02$, no. $=11)$ when the spontaneous labour group was considered separately. Neither the maternal gastrin level $(P>0 \cdot 1)$ nor the cord gastrin level $(P>0 \cdot 2)$ was affected by the infusion.

Cord and day 4 gastrin levels. The fourth day gastrin level was higher than the cord level ( $\mathbf{P}$ $<0.001$, no. $=19)$, and there was a correlation between them $(P<0.001)$ (Fig. 2). These observations were also true when the induced and spontaneous groups were considered separately. Other parameters such as parity, Apgar score, postmaturity, sex of the baby, birthweight, duration of labour, blood glucose level at day 4, or drop in blood glucose from birth to day 4, did not appear to influence the gastrin levels. 


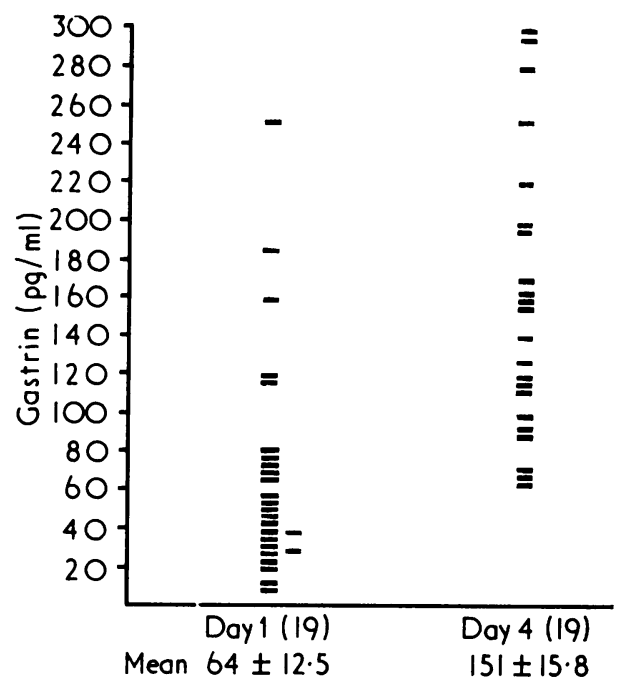

Fig. 2.-Plasma gastrin levels in the cord venous sample (day 1), and on the fourth day of the 19 neonates studied.

\section{Glucagon levels.}

C-terminal reactive GLI (pancreatic glucagon). The mean cord level was higher than the maternal level of the group as a whole $(P<0 \cdot 001$, no. $=22)$ (Fig. 3). This was true also when the induced

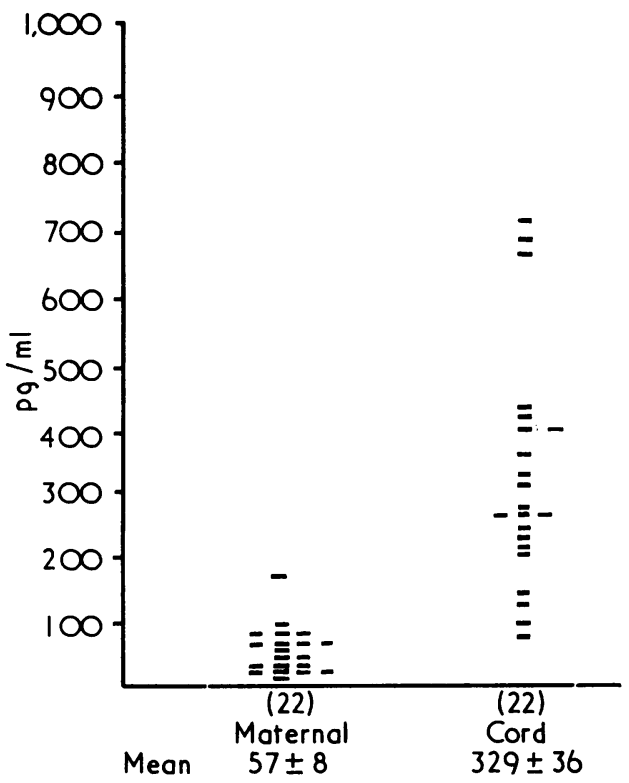

Fig. 3.-Plasma C-terminal reactive GLI levels in 22 mothers after labour and in the cord vein.
$(P<0.001)$ and the spontaneously born groups $(P<0.001)$ were considered separately. However, the cord level was higher in the babies born spontaneously $(P<0.005$, no. $=11)($ Fig. 4$)$, and

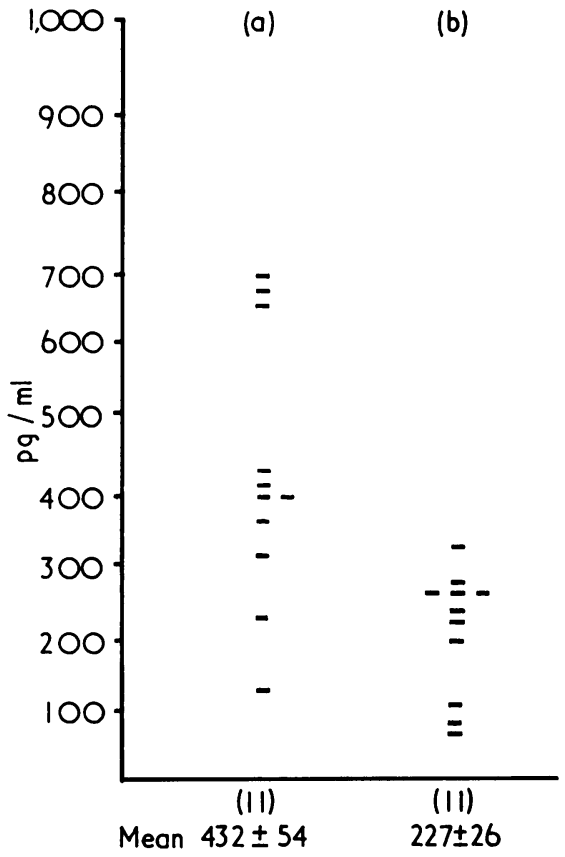

FIG. 4.-Plasma C-terminal reactive GLI in the cord vein of babies born after (a) spontaneous or (b) oxytocin-induced labour. The number of babies whose mothers received or did not receive oxytocin is shown.

the increment from the maternal to the cord value was also greater in the spontaneously born baby $(P<0.005$, no. $=11)$. A significant increase $(P<0 \cdot 05$, no. $=19)$ had occurred by the fourth day of life (Fig. 5), but there was no individual correlation between the cord and the day 4 value.

There was no significant relation either at birth or on day 4 between blood glucose or decrease in blood glucose and the C-GLI level. Similarly, there was no apparent relation between the C-GLI level and the Apgar score, birthweight, or sex of the baby.

$N$-terminal reactive $G L I$. The mean cord level was again significantly greater $(P<0.001$, no. $=22)$ than the maternal level (Fig. 6), and there was no individual correlation. Oxytocin infusion did not influence these findings and by the fourth day of life a significant increase $(P<0.001$, no. $=19)$ had occurred (Fig. 7). No relation could be deduced 


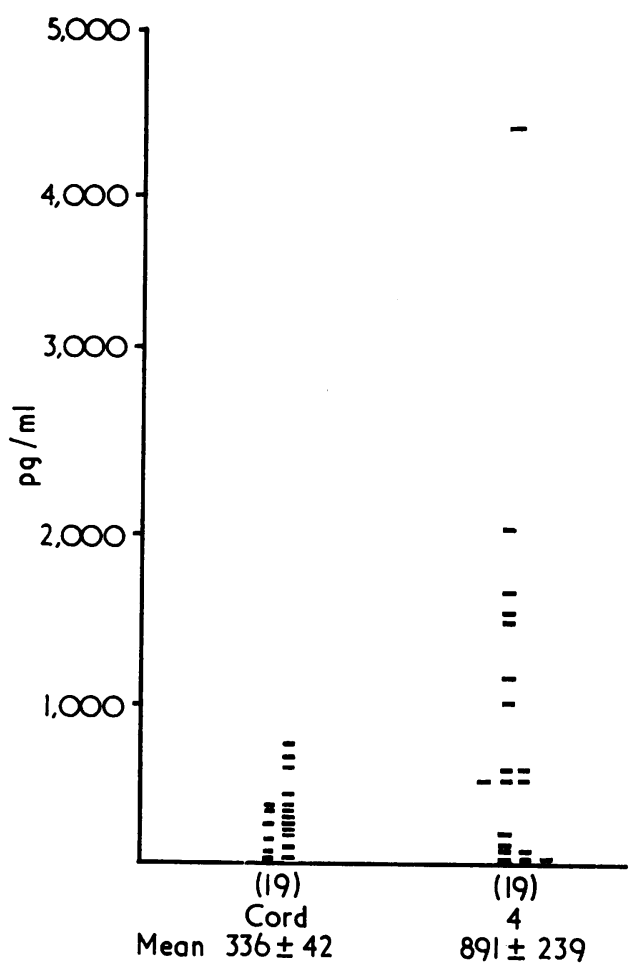

Fig. 5.-Plasma C-terminal reactive GLI levels in the cord venous sample and on the fourth day of 19 neonates.

between the N-GLI level and the blood glucose level, Apgar score, birthweight, or sex of the baby.

\section{Discussion}

These studies were undertaken in an attempt to explain the phenomenon of neonatal gastric hyperacidity. Our working hypothesis was that a maternal component of cord gastrin would be responsible for the temporary hyperacidity seen soon after birth. While this hypothesis is by no means proved, some interesting facts have emerged.

(1) Our results appear to show that the newly born baby secretes gastrin independently. The short half-life of gastrin makes it highly unlikely that any transferred maternal gastrin will persist until the fourth day of life (Ganguli et al., 1970). Hence, the highly significant correlation between the day 4 and cord levels probably reflects a common dependence upon neonatal secretion.

(2) There are two ways to explain the rise in gastrin levels by the fourth day of life. Firstly, it

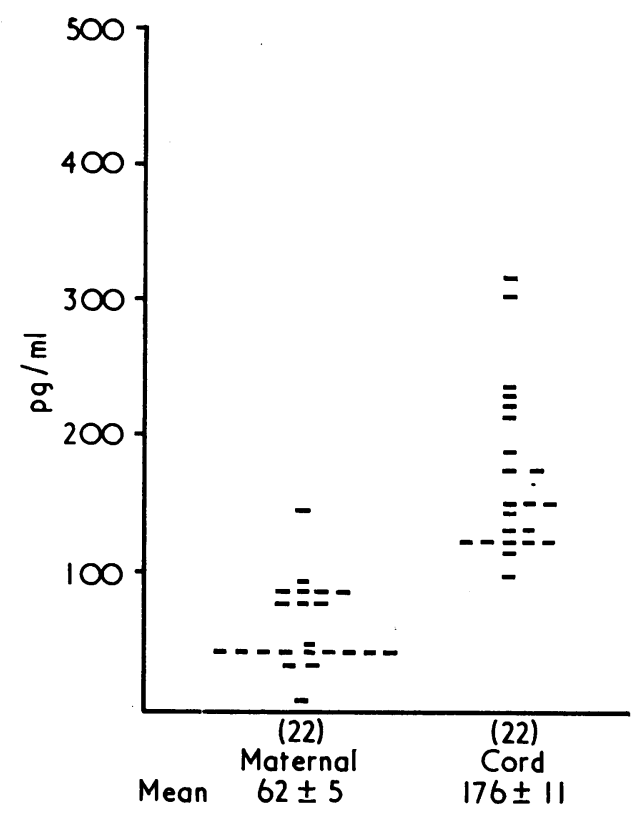

FIG. 6.-Plasma $N$-terminal reactive GLI in 22 mothers after labour and in the cord vein.

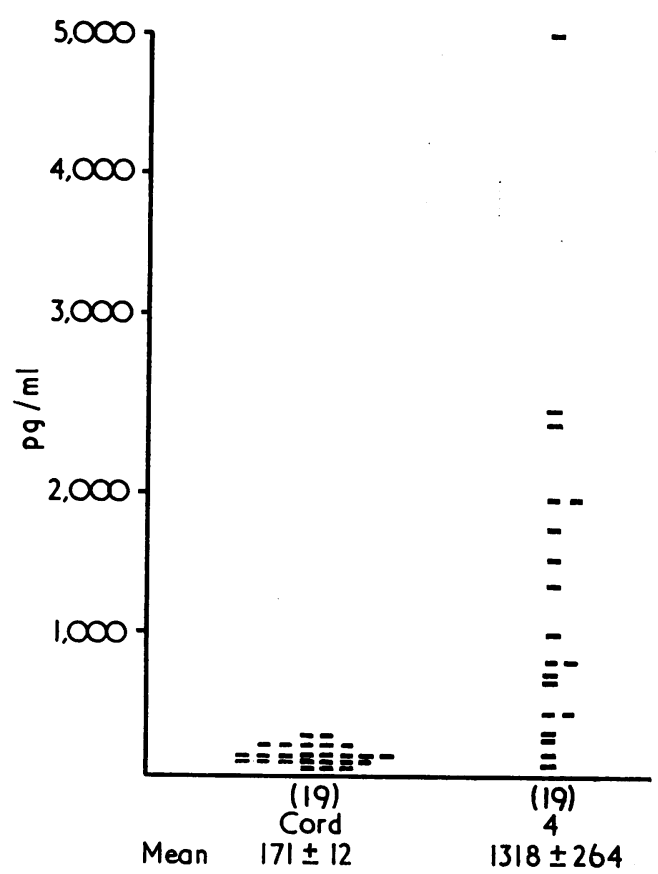

FIG. 7.-Plasma $N$-terminal reactive $G L I$ levels in the cord vein and on the fourth day in 19 neonates. 
may reflect a decrease in antral acidity from birth to day 4. This explanation would require a properly functioning, stable, negative feed-back mechanism between antral acidity and gastrin secretion (Trudeau and MacGuigan, 1971). However, the first gastric juice obtained at birth tends to be relatively neutral due to swallowed liquor (Ebers $e t$ al., 1956; Avery et al., 1966). Therefore, a further significant decrease in acidity by day 4 would mean that the fasting juice would be in the alkaline range. We feel that this would be unlikely since previous studies have revealed detectable acidity on the fourth day of life (Miller, 1941).

Accordingly, we have favoured the alternative explanation for this rise in gastrin levels by day 4, i.e. a maturing ability to secrete gastrin at any given antral acidity. This may also be considered as being due to a change in sensitivity of the negative feed-back mechanism.

(3) The effect of oxytocin infusion during labour is to abolish the usual increment in gastrin levels from mother to baby. The reason for the oxytocin infusion was the suspicion of postmaturity (a difficult term to define) in most cases, though there was evidence of slight toxaemia in one mother. In short, the evidence presented here supports the concept of maternal transfer of gastrin to the baby born spontaneously at term. Oxytocin infusion during labour may reduce cord gastrin levels by abolishing or inhibiting this transfer. This observation suggests that if maternal transfer occurs it occurs at least in part during the labour process.

Glucagon-like immunoreactivity in the plasma is derived both from the pancreas and the gut (Heding, 1971). The functions of the gut GLI are uncertain. Pancreatic GLI, however, acts in concert with insulin to ensure an adequate supply of glucose, free fatty acids, and ketones to the cell (Samols et al., 1966). It is secreted in reponse to fasting and acute hypoglycaemia and insulin inhibits this secretion (Lefebvre and Unger, 1972). The immunoassay levels in general correlate well with biological activity (Marco, Faloona, and Unger, 1971). It is possible to partly distinguish between pancreatic and gut GLI by using two antibodies, only one of which cross-reacts strongly with gut glucagon (Buchanan et al., 1974). In the classical terminology, total GLI would be N-GLI and pancreatic glucagon would be represented by C-GLI.

(4) Our results show that the newborn baby secretes both C-GLI and N-GLI independently at birth. The cord levels are greater than the maternal levels and a significant increase has occurred by the fourth day of life. As it is known that glucagon inhibits the gastric acid secretory effect of pentagastrin (Christiansen and Hendel, 1973), this glucagon rise may explain why the gastric acidity is low on day 4 despite high gastrin blood levels.

(5) It is interesting to find that oxytocin has the same effect on C-GLI levels as it has on gastrin, in that both the cord value and the increment from the maternal to the cord value is reduced when it has been used. Previous reports about glucagon levels at birth have concluded that there is no transfer of maternal glucagon to the baby at term (Milner et al., 1973; Johnston et al., 1972). However, in one investigation, a bidirectional transplacental exchange of exogenous pancreatic glucagon was observed in monkeys (Chez et al., 1970). In general, these reports have not distinguished between C-GLI and N-GLI and fail to state whether labour was spontaneous or induced. Our results are compatible with the transfer of C-GLI from the mother to the spontaneously born baby at term. Oxytocin infusion may reduce or abolish such a transfer.

(6) The C-GLI level and the blood glucose level were not related either at birth or on the fourth day. Previous investigations (Milner et al., 1973; Luyckx et al., 1972) have shown that pancreatic glucagon levels at birth are not related to blood glucose levels. It appears from our findings that this is true at least up to the fourth day of life.

In summary then, the idea that a maternal component of cord gastrin is responsible for neonatal gastric hyperacidity is an attractive one and is not excluded by our findings.

These studies were supported by grants from G. D. Searle and Co. and the Northern Ireland Hospitals Authority. We thank Mr. John Grant, Consultant Paediatric Surgeon, Stobhill Hospital, Glasgow, for criticism, and the nursing midwives and sisters of Stobhill Hospital for co-operation.

\section{REFERENCES}

Ardill, J. (1973). The measurement of gastrin by radio-immunoassay. Ph.D. Thesis. University of Belfast.

Avery, G. B., Randolph, J. G., and Weaver, T. (1966). Gastric acidity in the first day of life. Pediatrics, 37, 1005.

Buchanan, K. D., Flanagan, R. W. J., Murphy, R. F., O'Connor, F. A., and Shahidullah, M. (1974). Immunological characterisation of glucagon-like immunoreactivity. European fournal of Clinical Investigation. (In the press.)

Chez, R. A., Mintz, D. H., Horger, E. O., and Hutchinson, D. L. (1970). Factors affecting the response to insulin in the normal sub-human pregnant primate. fournal of Clinical Investigation, $49,1517$. 
Christiansen, J., and Hendel, L. (1973). The effect of glucagon on pentagastrin-induced acid secretion and serum calcium concentration in man. Scandinavian fournal of Gastroenterology, 8 , 81.

Ebers, D. W., Smith, D. I., and Gibbs, G. E. (1956). Gastric acidity on the first day of life. Pediatrics, 18, 800 .

Ganguli, P. C., Elder, J. B., Smith, I. S., and Hunter, W. M. (1970) The half-life of synthetic human gastrin in man. British Fournal of Surgery, 57, 848.

Gregory, R. A., and Tracy, H. J. (1964). The constitution and properties of two gastrins extracted from hog antral mucosa. Gut, 5, 103.

Griswold, C., and Shohl, A. T. (1925). Gastric digestion in newborn infants. American fournal of Diseases of Children, 30, 541.

Heding, L. G. (1971). Radioimmunological determination of pancreatic and gut glucagon in plasma. Diabetologia, 7, 10.

Hess, A. F. (1913). The gastric secretion of infants at birth. American fournal of Diseases of Children, 6, 264

Johnston, D. I., Bloom, S. R., Greene, K. R., and Beard, R. W. (1972). Plasma pancreatic glucagon relationship between mother and foetus at term. Fournal of Endocrinology, 55, xxv.

Jorgensen, K. H., and Larsen, U. D. (1972). Purification of 125I-glucagon by anion exchange chromatography. Hormone and Metabolic Research, 4, 223.

Lefebvre, P. J., and Unger, R. H. (1972). Glucagon: Molecular Physiology, Clinical and Therapeutic Implications, p. 213. Pergamon Press, Oxford.

Levinson, S. A., and MacFate, R. P. (1937). Clinical Laboratory Diagnosis, p. 616. Lea and Febiger, Philadelphia.
Luyckx, A. S., Massi-Benedetti, F., Falorni, A., and Lefebvre, P. J. (1972). The presence of pancreatic glucagon in the portal plasma of human neonates. Differences in the insulin and glucagon responses to glucose between normal infants and infants from diabetic mothers. Diabetologia, 8, 296.

Marco, J., Faloona, G. R., and Unger, R. H. (1971). The glycogenolytic activity of immunoreactive pancreatic glucagon in plasma. Fournal of Clinical Investigation, 50, 1650.

Miller, R. A. (1941). Observations on the gastric acidity during the first month of life. Archives of Disease in Childhood, 16, 22.

Milner, R. D. G., Chouksey, S. K., Mickleson, K. N. P., and Assan, R. (1973). Plasma pancreatic glucagon and insulin/glucagon ratio at birth. Archives of Disease in Childhood, 48, 241.

Murphy, R. F., Buchanan, K. D., and Elmore, D. T. (1973). Isolation of glucagon-like immunoreactivity of gut by affinity chromatography on anti-glucagon antibodies coupled to sepharose 4B. Biochimica et Biophysica Acta, 303, 118.

Samols, E., Tyler, J., Megysi, C., and Marks, V. (1966). Immunochemical glucagon in human pancreas, gut, and plasma. Lancet, 2, 727.

Trudeau, W. L., and MacGuigan, J. E. (1971). Relations between serum gastrin levels and rates of gastric hydrochloric acid secretion. New England fournal of Medicine, 284, 408.

Correspondence to Mr. I. M. Rogers, FRCS, 24 Westfields, Rookery Park, Bishopbriggs, Glasgow. 